\title{
Mechanistic pathways of mercury removal from the organomercurial lyase active site
}

Pedro J Silva, Viviana Rodrigues

Bacterial populations present in Hg-rich environments have evolved biological mechanisms to detoxify methylmercury and other organometallic mercury compounds. The most common resistance mechanism relies on the $\mathrm{H}^{+}$-assisted cleavage of the $\mathrm{Hg}-\mathrm{C}$ bond of methylmercury by the organomercurial lyase MerB. Although the initial reaction steps which lead to the loss of methane from methylmercury have already been studied experimentally and computationally, the reaction steps leading to the removal of $\mathrm{Hg}^{2+}$ from MerB and regeneration of the active site for a new round of catalysis have not yet been elucidated. In this paper, we have studied the final steps of the reaction catalyzed by MerB through quantum chemical computations at the combined MP2/CBS//B3PW91/6$31 G(d)$ level of theory. While conceptually simple, these reaction steps occur in a complex potential energy surface where several distinct pathways are accessible and may operate concurrently. The only pathway which clearly emerges as forbidden in our analysis is the one arising from the sequential addition of two thiolates to the metal atom, due to the accumulation of negative charges in the active site. Addition of two thiols, in contrast, leads to two feasible mechanistic possibilities. The most straightforward pathway proceeds through proton transfer from the attacking thiol to Cys159, leading to its removal from the mercury coordination sphere, followed by a slower attack of a second thiol, which removes Cys96. The other pathway involves Asp99 in an accessory role similar to the one observed earlier for the initial stages of the reaction and affords a lower activation enthalpy, around $14 \mathrm{kcal}^{\mathrm{mol}}{ }^{-1}$, determined solely by the cysteine removal step rather than by the thiol ligation step. Addition of one thiolate to the intermediates arising from either thiol attack occurs without a barrier and produces an intermediate bound to one active site cysteine and from which $\mathrm{Hg}\left(\mathrm{SCH}_{3}\right)_{2}$ may be removed only after protonation by solvent-provided $\mathrm{H}_{3} \mathrm{O}^{+}$. Thiolate addition to the active site (prior to any attack by thiols) leads to pathways where the removal of the first cysteine becomes the rate-determining step, irrespective of whether Cys159 or Cys96 leaves first. Comparisons with the recently computed mechanism of the related enzyme MerA further underline the important role of Asp99 in the energetics of the MerB reaction. Kinetic simulation of the mechanism derived from our computations strongly suggests that in vivo the thiolate-only pathway is operative, and the 
Asp-assisted pathway (as well as the conversion of intermediates of the thiolate pathway into intermediates of the Cys-assisted pathway) is prevented by steric factors absent from our model and related to the precise geometry of the organomercurial binding-pocket. 
Pedro J. Silva and Viviana A. B. Rodrigues

FP-ENAS/Fac. de Ciências da Saúde, Univ. Fernando Pessoa, Rua Carlos da Maia, 296, 4200150 Porto-Portugal 


\section{Introduction}

4 Mercury is naturally present in the environment, especially at specific geologically enriched

5 regions along tectonical plate boundaries (Varekamp \& Buseck, 1986), where it can be found as

6 the characteristically colored cinnabar ores $(\mathrm{HgS})$. Though quite insoluble in water $(\approx 10 \mu \mathrm{g} / \mathrm{L})$,

7 the solubilized species $\left(\mathrm{Hg}^{2+}\right)$ may be readily uptaken by methanogens and sulfate-reducing

8 bacteria, which then methylate it to methylmercury (Barkay, Miller \& Summers, 2003; Lin, Yee

$9 \&$ Barkay, 2012) through the combined action of the reductive acetyl-CoA pathway (Choi, Chase

10 \& Bartha, 1994) and two novel proteins: a methyl-binding corrinoid-containing protein (HgcA)

11 and a corrinoid-reducing protein with unknown physiological function(Parks et al., 2013). The

12 methylmercury thus formed is highly soluble in lipids and therefore tends to accumulate in living

13 tissues and to be concentrated along the food chain. The solution reactivity of mercury towards

14 soft ligands(Riccardi et al., 2013) like the thiols present in cysteine-containing proteins is

15 responsible for the high toxicity of methylmercury(Eto, Marumoto \& Takeya, 2010), especially

16 towards lipid-enriched cells (like those of the nervous system) where its solubility is the highest.

17 Bacterial populations present in Hg-rich environments have therefore evolved biological

18 mechanisms to detoxify methylmercury and other organometallic mercury compounds. The most

19 common resistance mechanism relies on proton-assisted cleavage of the $\mathrm{Hg}-\mathrm{C}$ bond of

20 methylmercury by the organomercurial lyase MerB(Begley, Walts \& Walsh, 1986a,b), and

21 sequential transfer of the remaining $\mathrm{Hg}^{2+}$ ion to a flavoprotein (MerA) which reduces the cation

22 to its metallic form(Fox \& Walsh, 1982; Ledwidge et al., 2005, 2010). 
23 Extensive experimental studies(Begley et al., 1986a,b; Pitts \& Summers, 2002; Di Lello et al., 24 2004; Lafrance-Vanasse et al., 2009) have elucidated the structure of MerB and established that 25 this enzyme does not require any cofactors and uses two thiols (like cysteine or glutathione, but 26 not dithiothreytol(Pitts \& Summers, 2002)) as co-reactants for every mercury organic compound 27 cleaved. A pioneering computational study(Parks et al., 2009) has shown that in the active site 28 any one of two conserved Cys residues (Cys 96 and Cys 159) may, upon deprotonation, complex 29 the $\mathrm{Hg}$ moiety of the substrate. A proton is then transferred from the other conserved Cys to a 30 conserved acidic residue (Asp 99), which subsequently acts as a proton donor to the leaving alkyl 31 or aryl group. That study did not, however, address the reaction steps leading to the loss of $\mathrm{Hg}^{2+}$ 32 from MerB and regeneration of the active site for a new round of catalysis. In this contribution, 33 we use quantum chemical computations to analyze the possible reaction mechanisms. The 34 application of these methods to protein active sites (reviewed e.g. in (Himo \& Siegbahn, 2003;

35 Ramos \& Fernandes, 2008)) allows the characterization of enzyme-bound intermediates and 36 transition states which (due to their transient nature) are not amenable to experimental 37 characterization and the evaluation of thermodynamic and kinetic feasibility of postulated 38 mechanisms. The results show that complexation of $\mathrm{Hg}^{2+}$ by extraneous thiols is most likely to 39 proceed through the attack by one protonated and one deprotonated thiol, rather than by two 40 deprotonated thiols. The precise order of attack seems to be arbitrary, and an important role of 41 the $\mathrm{Hg}^{2+}$-coordinating Asp99 residue in lowering the reaction energy was found.

\section{Methods}


The active site geometry was built from PDB:3F0P, the crystal structure of the mercury-bound form of MerB(Lafrance-Vanasse et al., 2009). The active site included the conserved residues Cys96, Asp 99, Cys 159, the mercury ion and Hg-complexing water molecule. To prevent unrealistic motions of the active site, the $C \alpha$ and $C \beta$ atoms of every aminoacid were constrained to their crystallographic positions. All calculations were performed at the B3PW91 level of theory(Perdew, 1991; Becke, 1993), which has been commonly used in the study of Hgcontaining complexes(Barone et al., 1997; Ni et al., 2006; Parks et al., 2009; Li et al., 2010; Riccardi et al., 2013). Autogenerated delocalized coordinates(Baker, Kessi \& Delley, 1996) were used for geometry optimizations, using the SDD effective core-potential and associated basis set(Häussermann et al., 1993) for $\mathrm{Hg}$ and the 6-31G(d) basis set for all other atoms. More accurate DFT energies of the optimized geometries were calculated with a triple- $\zeta$ quality basis set, 6-311+G(d). Zero point (ZPE) and thermal effects $(\mathrm{T}=298.15 \mathrm{~K}, \mathrm{P}=1$ bar) were evaluated using a scaling factor of 0.9804 for the computed frequencies. All computations were performed with the Firefly quantum chemistry package, which is which is partially based on the GAMESS (US)(Schmidt et al., 1993) source code. Environmental contributions to the energies of the stationary points and transition states were computed with the polarizable conductor model(Tomasi \& Persico, 1994; Mennucci \& Tomasi, 1997; Cossi et al., 1998), with dielectric constants ranging from 4 (usually chosen for protein-embedded active sites) to 78.36 (mimicking a completely exposed active site). Dispersion and repulsion effects were evaluated as described by Amovilli and Mennucci(Amovilli \& Mennucci, 1997). MP2 single-point energies were computed on the optimized geometries using the aug-cc-pVDZ-PP (or aug-ccpVTZ-PP) basis set(Peterson \& Puzzarini, 2005) for mercury and cc-pVDZ (or cc-pVTZ basis sets) for all other elements, and extrapolated to the complete basis set limit (CBS-MP2) as described by 
68 Truhlar(Truhlar, 1998). Solution MP2 values were obtained by applying the DFT solvation 69 energies to the gas-phase CBS-MP2 energies. Numerical integration of the rate equations of the

70 kinetic model derived in this work was performed using a self-built program, which is available 71 for download, together with respective outputs, at

72 http://dx.doi.org/10.6084/m9.figshare.1433993.

73 


\section{$75 \quad$ Results}

possible (Fig. 1), depending on the protonation state of each mercury-attacking ligand (thiol vs. thiolate), on whether Cys96 or Cys159 is first ejected from the coordination sphere of the Hg ion, and on whether the protonation state of Asp99 changes throughout the cycle. Our densityfunctional computations show that extraneous methanethiol is not nucleophilic enough to 82 directly the attack of the enzyme-bound $\mathrm{Hg}^{2+}$. The moderate acidity of the thiol, however, allows 83 it to transfer a proton to one of the $\mathrm{Hg}^{2+}$ ligands (either Cys159 or Asp 99), in a process which 84 both weakens the ligand-to-metal bond and transforms the thiol into a (much more nucleophilic) 85 thiolate (Figure 2). Proton transfer to Cys159 (Figure 2B) occurs with a small barrier (12.3$12.8 \mathrm{kcal}_{\mathrm{mol}}^{-1}$ in MP2, $7.8-8.0 \mathrm{kcal}^{\mathrm{mol}}{ }^{-1}$ using DFT) and is moderately exergonic by $7-9$

$87 \mathrm{kcal} . \mathrm{mol}^{-1}$. This activation barrier is very similar to the barrier found experimentally(Hong et al., 88 2010) for the initial attack of MerB-bound mercury by free glutathione $\left(2.5 \times 10^{4} M^{-1} \mathrm{~s}^{-1}\right.$, which

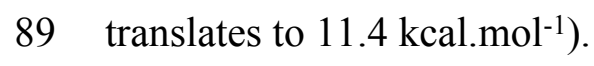

90 Addition of a second thiol to the singly-cysteinated $\mathrm{Hg}^{2+}$ is quite similar to that of the first 91 thiol, as expected from the identical composition of coordination sphere around the metal atom 92 (a carboxylate and two thiols). The most interesting difference arises from the possibility of 93 proton transfer to Cys96 (in the Cys96-bound Int2) due to the newly-found flexibility of the 94 freed Cys159 sidechain. This step (Figure 2D-F) has a larger barrier $\left(15.8-18.1 \mathrm{kcal}^{\mathrm{mol}}{ }^{-1}\right.$ 95 using MP2, $14.5-14.8 \mathrm{kcal}_{\mathrm{mol}}^{-1}$ in DFT) than the addition of the first thiol because the larger 96 thiol(ate) $-\mathrm{Hg}$ distance in the latter transition state $(2.875$ vs $2.685 \AA$ ) entails a smaller 
97 stabilization due to lower overlap between thiol(ate) and $\mathrm{Hg}$ orbitals. In the gas phase,

98 regeneration of the active site through the removal of $\mathrm{Hg}\left(\mathrm{SCH}_{3}\right)_{2}$ from Asp99 leads to a

99 continuous increase in electronic energy of approximately $26 \mathrm{kcal}^{\mathrm{mol}} \mathrm{l}^{-1}$. In solution, however,

100 the reaction is only moderately endergonic $\left(1-6 \mathrm{kcal} \cdot \mathrm{mol}^{-1}\right.$,depending on the dielectric constant $)$

101 since the presence of a compact negative charge in the Asp99 residue in the product state leads to

102 a stronger solvation of the separated fragments, which largely offsets the gas-phase energy

103 increase due to the severing of the Hg-carboxylate bond.

104 If the initial conformation of the attacking thiol, in contrast to that depicted in Figure 2, has the

$105 \mathrm{~S}-\mathrm{H}$ bond aligned towards Asp99, $\mathrm{H}^{+}$-transfer to Asp99 occurs instead, without any

106 thermodynamic barrier (Figure 3A). This transfer is favorable by $15 \mathrm{kcal}^{\mathrm{mol}}{ }^{-1}$ and may be

107 followed by a further movement of the proton from Asp99 to the distal Cys96 Hg-ligand (Figure

108 3B), which is thus released from the metal (Figure 3C). This proton-transfer step has a moderate

109 barrier around 12-14 $\mathrm{kcal}^{\mathrm{mol}}{ }^{-1}$, and should therefore occur at a rate similar to that of the direct

110 protonation and removal of the Cys159 ligand depicted in the alternative mechanism above

111 (Figure2A-C). Addition of a second thiol may again proceed in an Asp99-assisted fashion

112 (Figure 3D-F): proton transfer from the thiol to the Asp99 ligand of the Cys159-bound Int2 is

113 favored by $10-11 \mathrm{kcal}^{-\mathrm{mol}^{-1}}$ but must now overcome a small barrier $\left(4 \mathrm{kcal}^{\mathrm{mol}}{ }^{-1}\right)$, in contrast

114 to the barrier-free process observed when this movement is the first step of the reaction 115 sequence.

116 In contrast to the addition of cysteine thiols analyzed above, addition of a cysteine thiolate to

117 the MerB-bound $\mathrm{Hg}^{2+}$ proceeds unhindered, i.e. without any energetic barrier. The tetra-

118 coordinated intermediate formed (Int1) lies $12-13 \mathrm{kcal}^{\mathrm{mol}} \mathrm{l}^{-1}$ below the infinitely-separated

119 reactants (in MP2; $6-7 \mathrm{kcal}^{\mathrm{mol}}{ }^{-1}$ below reactants in DFT), and may then shed any of its Cys- 
120 ligands upon overcoming a moderate $14.0-15.5 \mathrm{kcal}^{\mathrm{mol}}{ }^{-1}$ barrier. Addition of a second thiolate

121 to this complex, however, is much costlier due to the electrostatic repulsion between the freed,

122 deprotonated, Cys and the negatively-charged thiolate. The precise cost depends very steeply on

123 the chosen dielectric constant (Table 3), as expected for a reaction involving highly localized

124 charges, but the transition state for this step always remains more than $25 \mathrm{kcal}^{\mathrm{mol}} \mathrm{l}^{-1}$ above Int1,

125 far above the $16-20 \mathrm{kcal}^{\mathrm{mol}}{ }^{-1}$ expected(Parks et al., 2009) for the rate-limiting step of this

126 enzyme from the application of the Eyring equation, $k_{c a t}=\frac{k_{B} T}{h} e^{-\frac{\Delta G^{\ddagger}}{R T}}$, to the experimentally

127 observed reaction rate(Begley et al., 1986b). Since methanethiol is weakly acidic ( $\mathrm{pKa}=10.4)$ and

128 is almost completely protonated at physiological $\mathrm{pH}$, the initial cost of deprotonating it must be

129 added to the computations above. This cost amounts to -RT $\ln 10^{\mathrm{pH}-\mathrm{pKa}}$ (Ullmann \& Knapp, $1301999)$, or $4.6 \mathrm{kcal}^{\mathrm{mol}} \mathrm{l}^{-1}$ at $\mathrm{pH}=7$.

131 So far, we have only described the reaction mechanism arising from the addition of two thiols 132 with the same protonation state. We now turn to the analysis of mechanism involving distinct 133 protonation states of the attacking thiols: inded, the two N-terminal cysteines of MerA which 134 catalyze removal of $\mathrm{Hg}^{2+}$ from MerB in vivo (Ledwidge et al., 2005) have been shown to possess 135 widely separated $\mathrm{pK}_{\mathrm{a}}$ 's (Ledwidge et al., 2010) which entail that at physiological $\mathrm{pH}$ one of them 136 is expected to remain mostly unprotonated while the other only deprotonates at high $\mathrm{pH}$.

137 Addition of a thiolate to any of the forms of thiol-based intermediate 2 (where $\mathrm{Hg}^{2+}$ is bound to 138 either of Cys159 or Cys96) occurs spontaneously without any energetic barrier. In the Cys159-

139 bound form the reaction product has a slightly lower energy than in the Cys96-bound form and 140 adopts a more exposed conformation (Figure 5, panel D). The metal ion in the resulting 141 intermediate 3 ' has a sulfur-only coordination sphere in both instances, as the interactions with 142 Asp99 have disappeared(Figure 5, panels B and D). 
143 Reaction of a thiol with the thiolate-based C96-bound/C159-deprotonated intermediate

144 proceeds readily through proton transfer from the attacking thiol to the deprotonated Cys 159 and

145 immediate thiolate attack of the metal atom. This process occurs without an electronic barrier

146 and yields C96-bound Int3' (Figure 5, panel B). On the other hand, the thiolate-based C159-

147 bound intermediate 2 is susceptible to attack by a thiol in an Asp99-dependent manner (Figure 5,

148 panel F). As in the other Asp99-assisted thiol attacks analyzed above, the electronic barrier to

149 this process is negligible (Figure 5, panel E) and yields an intermediate where Asp99 is

150 protonated and the mercury ion remains coordinated by three ligands (two external thiolates and

151 Cys159). This Cys159-bound/Cys96-deprotonated/Asp99-protonated intermediate (Int3 ${ }_{\mathrm{a}}$ ' in

152 Figure 5, panel E) spontaneously decays, through a negligible energetic barrier $\left(<1 \mathrm{kcal} . \mathrm{mol}^{-1}\right)$,

153 to the Cys159 bound/ Cys96-protonated/Asp99-deprotonated state.

154 The overall reaction barrier for all of the mechanisms involving attack of the $\mathrm{Hg}^{2+}$ ion by a

155 thiol and a thiolate therefore depends on the barrier of the first attack, which was computed 156 above (Tables 1-3) to lie between 12 and $15 \mathrm{kcal}^{\mathrm{mol}}{ }^{-1}$ in all instances. Since the 3-4 kcal.mol-1

157 difference between the barriers of these alternatives is equivalent to the intrinsic error of the

158 computational protocols used, further discrimination between these three possibilities is

159 unfortunately not possible at this stage.

160 Regeneration of the initial state of the active site from the Int3' intermediate now requires the 161 severing of the remaining Hg-Cys bond. Preliminary attempts at the characterization of this

162 reaction step showed that direct stretching of the $\mathrm{Hg}$-Cys bond is energetically quite costly. Our

163 results above (Table 2), however, show that protonation of the metal-bound Cys dramatically

164 weakens the $\mathrm{Hg}-\mathrm{S}$ bond. We have therefore analyzed the feasibility of removing $\mathrm{Hg}\left(\mathrm{SCH}_{3}\right)_{2}$

165 from the active site cysteine through direct protonation by solvent-provided $\mathrm{H}_{3} \mathrm{O}^{+}$. A few explicit 
166 water molecules were also added to the model to provide an appropriate description of the

167 solvated hydronium ion (Figure 6).

168 As mentioned above, two different conformations of the Int3' intermediate exist: an extended

169 conformation (Figure 5D) where $\mathrm{Hg}\left(\mathrm{SCH}_{3}\right)_{2}$ is bound to Cys159 and a compact conformation

170 where the product is bound to Cys96, instead (Figure 5B). In the compact conformation (Figure

171 6) this proton transfer is spontaneous by $6.6 \mathrm{kcal}^{\mathrm{mol}}{ }^{-1}$ (according to MP2; $2.7 \mathrm{kcal}^{\mathrm{mol}}{ }^{-1}$

172 according to DFT) and diffusion-controlled: the very small energetic barrier found during the

173 geometry optimization completely disappears upon inclusion of solvation, zero-point and

174 vibrational effects. Upon removal of Cys96, Asp99 weakly attaches to the mercury ion,

175 preventing the product from freely diffusing away from the active site. Complete removal of

$176 \mathrm{Hg}\left(\mathrm{SCH}_{3}\right)_{2}$ occurs upon stretching this very weak Asp-Hg bond, at a cost of only $4.1 \mathrm{kcal} . \mathrm{mol}^{-1}$.

177 In the "extended" conformation of Int3', the $\mathrm{Hg}\left(\mathrm{SCH}_{3}\right)_{2}$ moiety lies quite far from Asp99, which

178 modifies the mechanistic analysis due to the impossibility of Asp99-attachment to the metal

179 upon the release of Cys159. In contrast to the previous analysis, in this conformation the solvated

$180 \mathrm{H}_{3} \mathrm{O}^{+}$is unstable even before including bulk solvation effects implicitly through the PCM model.

181 Instead, two separate minima arise: an unproductive intermediate featuring a proton on the

182 Asp99 residue (Figure 7A), and the Cys159-protonated product featuring a free $\mathrm{Hg}\left(\mathrm{SCH}_{3}\right)_{2}$

183 (Figure $7 \mathrm{C}$ ). Both minima lie $\approx 10 \mathrm{kcal}^{\mathrm{mol}}{ }^{-1}$ below the postulated initial (meta-stable)

184 conformation featuring a solvated $\mathrm{H}_{3} \mathrm{O}^{+}$(Figure 7B).

\section{Kinetic simulations}


187 Extensive experimental analysis of the reaction of Hg-bound MerB with glutathione or the

188 physiological partner (Hong et al., 2010) has shown that MerA is able to effect complete metal

189 removal even at very low concentrations $(50 \mu \mathrm{M})$, whereas concentrations of monothiols below

$19010 \mathrm{mM}$ afford only partial protein demetallation. Numerical simulation of the complete reaction

191 mechanism described in this work (Figure 8) reveals a very good agreement with experiment,

192 provided that a protonated thiol is prevented from performing the initial attack on the mercury

193 ion (Figure 9, panels A and B): operation of the Asp-assisted pathway (either alone or in concert

194 with other pathways) would always lead to complete removal of mercury from the MerB active

195 site (Figure 9, panel C) due to the high exergonicity of the initial formation of the Asp-

196 protonated form of Int1 intermediate (Figure 3A and Table 2). Simultaneous operation of the

197 Cys-assisted pathways would in turn allow the C96-bound Int3' intermediate (formed mainly in

198 the thiolate pathway, which has a more exergonic first reaction than the Cys-assisted thiol attack

199 pathway) to be diverted through thiolate loss (reaction $\mathrm{k}_{6}$ in Figure 8) to the Cys-assisted

200 pathway, yielding a complex kinetic profile which ultimately leads to total mercury removal

201 from MerB (Figure 9, panel D). In turn, setting the reaction rate of the $\mathrm{k}_{5}$ and $\mathrm{k}_{6}$ steps to zero (i.e.

202 preventing the conversion of Int2(C96-bound) into Int3'(C96-bound, and vice-versa), while

203 keeping the thiolate-only pathway and the rest of the Cys-assisted pathway operative yields a

204 kinetic profile indistinguishable from that of the thiolate-only pathway. Interestingly, identical

205 kinetic simulations using the DTT (which is a known inhibitor of MerB) failed to show any

206 inhibition. Agreement of our model with the experimental observations therefore requires that

207 the formation of Int1(protonated Asp) (Figure 8, reaction $k_{15} / k_{16}$ ), the conversion of Int2(C96-

208 bound) into Int3'(C96-bound) (Figure 8, reaction $\mathrm{k}_{5} / \mathrm{k}_{6}$ ), and the release of the Hg-DTT complex

209 from the active site, which are predicted by our small-model QM computations to be 
210 thermodynamically and kinetically feasible, are prevented in the enzyme, most likely due to the

211 intervention of steric factors arising from the rest of the protein. The proposed role of steric

212 factors in the overall kinetic profile of MerB is consistent with other experimental observation:

213 for example, though the trigonal complex of $\mathrm{Hg}$ bound by both sulfur atoms of DTT and by

214 Cys96 is long-lived in the absence of added thiols, $\mathrm{Hg}$ can be removed after a few minutes of

215 incubation with MerA or with incubation with very high concentrations of glutathione (Benison

216 et al., 2004). Since the chemically reactive portion in all these MerB co-substrates is the same,

217 this implies that the differences in behavior should not be based in purely electronic factors but

218 in the presence of intermolecular interactions between Hg-DTT and MerB (but not between Hg-

219 MerA and MerB, or between Hg-glutathione and MerB) which prevent its exit from the active

220 site. Indeed, preliminary experimental evidence (J. Omichinski, 2015, pers. comm.) suggests that

221 the N-terminal portion of MerB is responsible for trapping the Hg-DTT complex and the 222 observed partial inhibition of MerB activity by DTT.

224 Discussion

226 Our computations show that the final steps of the reaction catalyzed by MerB, while 227 conceptually simple, occur in a complex potential energy surface where several distinct 228 pathways are accessible and may operate concurrently. The only pathway which clearly emerges 229 as forbidden in our quantum chemical analysis is the one arising from the sequential addition of 230 two thiolates to the metal atom, due to the accumulation of negative charges in the active site.

231 Addition of two thiols, in contrast, leads to two feasible mechanistic possibilities. The most 
232 straightforward pathway proceeds through proton transfer from the attacking thiol to Cys159

233 (activation $\Delta \mathrm{H}=13 \mathrm{kcal}^{\mathrm{mol}}{ }^{-1}$ ), leading to its removal from the mercury coordination sphere,

234 followed by a slower attack of a second thiol, which removes Cys96 (activation $\Delta \mathrm{H}=16-18$

$\left.235 \mathrm{kcal}^{\mathrm{mol}}{ }^{-1}\right)$. Entropic effects, which we could not analyze due to the need of enforcing geometric

236 constraints on our active site model, may, however, easily place this pathway above the

237 experimentally determined activation $\Delta \mathrm{G}\left(16-20 \mathrm{kcal}^{\mathrm{mol}} \mathrm{m}^{-1}\right)$. The other pathway involves Asp99

238 in an accessory role similar to the one observed earlier for the initial stages of the reaction(Parks

239 et al., 2009) and affords a lower activation enthalpy, around $14 \mathrm{kcal}^{\mathrm{mol}}{ }^{-1}$, determined solely by

240 the removal of the first cysteine ligand rather than by the ligation of the second thiol. Unlike this

241 Asp99-assisted mechanism, the Cys-assisted pathway predicts the addition of the second thiol to

242 be rate-limiting, in marked disagreement with previous interpretations of experimental

243 results(Hong et al., 2010). In contrast, addition of one thiolate to the intermediates arising from

244 either thiol leads to pathways where the later reaction steps have negligible barriers. The

245 intermediate formed in this reaction (Int3') remains bound to one active site cysteine and may

246 shed $\mathrm{Hg}\left(\mathrm{SCH}_{3}\right)_{2}$ after protonation of this cysteine by solvent-provided $\mathrm{H}_{3} \mathrm{O}^{+}$. The activation

247 energy of this step in solution therefore depends on the solution $\mathrm{pH}$ according to equation:

248

$$
\Delta G^{\ddagger}=\Delta G^{0 \ddagger}+R T \ln \frac{1}{\left[H^{+}\right]}
$$

249 This protonation event is quite spontaneous and occurs without an energetic barrier $\left(\Delta \mathrm{G}^{0 \ddagger}=0\right)$,

250 leading to an effective $\Delta \mathrm{G}^{\star}=-\mathrm{RT} \ln 10^{-\mathrm{pH}}$, or $9.5 \mathrm{kcal}^{\mathrm{mol}} \mathrm{mol}^{-1}$ at $\mathrm{pH}=7$.

251 Thiolate addition to the active site (prior to any attack by thiols) leads to pathways where the 252 removal of the first cysteine becomes the rate-determining step (activation $\Delta \mathrm{H}=14-15 \mathrm{kcal}^{\mathrm{mol}}{ }^{-1}$, 253 irrespective of whether Cys159 or Cys96 leaves first). Asp99-assisted addition of a thiol to this 
254 intermediate then occurs without an energy barrier and yields the familiar Int3' intermediate

255 discussed above. A comparison of these results with the recently published computational

256 analysis of the transfer of $\mathrm{Hg}^{2+}$ from the $\mathrm{C}$-terminal cysteine pair of MerA to the buried cysteine

257 pair in the active site of MerA(Lian et al., 2014) affords additional insights on the relative

258 importance of the mercury-coordinating aminoacids. In that work, which included (unlike ours)

259 the influence of the remainder of the enzyme through a QM/MM formalism, thiol addition to a

$260 \mathrm{Hg}^{2+}$ ion coordinated by two cysteines was observed to proceed through a relatively high-energy

261 transition state $\left(20.4 \mathrm{kcal} . \mathrm{mol}^{-1}\right)$ and to be endergonic by $9.0 \mathrm{kcal} . \mathrm{mol}^{-1}$, in contrast to the $12-13$

262 kcal.mol ${ }^{-1}$ barrier and 9-10 kcal.mol ${ }^{-1}$ exergonicity we computed for the related addition of a

263 thiol to the MerB active site. Whereas the change in activation energy may be attributed to our

264 neglect of the surrounding protein environment and to the absence, in the MerA study, of a direct

265 proton transfer from the attacking thiol to the leaving Cys residue, further analysis points to

266 another reason. Indeed, the QM-only results reported by Lian et al. in their Figure 7 show that

267 neglect of the electrostatic influence of the protein brings the activation energy down to 12.6

$268 \mathrm{kcal}^{\mathrm{mol}} \mathrm{H}^{-1}$ (in perfect agreement with our data) but only lowers the reaction energy by 10

$269 \mathrm{kcal}^{\mathrm{mol}} \mathrm{H}^{-1}$ (instead of the $19 \mathrm{kcal}^{\mathrm{mol}}{ }^{-1}$ computed for the MerB reaction in our study). This

270 observation allows us to attribute this $9 \mathrm{kcal}_{\mathrm{mol}}^{-1}$ energy difference to the additional interaction,

271 in MerB, of Asp99 with the mercury ion. The influence of Asp99 is also noticeable in the steps

272 involving thiolate addition to mercury, which occur without a barrier in MerB but have an

273 activation energy of $9 \mathrm{kcal}^{\mathrm{mol}}{ }^{-1}$ in the QM-only MerA model and (in a smaller extent) in the

274 removal of a cysteine from a thiolate-attacked mercury, which has an activation energy of 11

$275 \mathrm{kcal}_{\mathrm{mol}}{ }^{-1}$ in the QM-only MerA model, compared to $15 \mathrm{kcal}^{\mathrm{mol}}{ }^{-1}$ in MerB. 
276 277 discriminate between the reaction pathways by comparing the kinetic profiles predicted by the 278 quantum-chemical computations with the wealth of experimental data obtained by Hong(Hong et 279 al., 2010) and Benison (Benison et al., 2004). This analysis strongly suggests that in vivo the 280 281 intermediates of the thiolate pathway into intermediates of the Cys-assisted pathway) is 282 prevented by steric factors absent from our model and related to the precise geometry of the 283 284 285 286 287 288

In spite of the similarity of the kinetic barriers of the different tested pathways, we were able to thiolate-only pathway is operative, and the Asp-assisted pathway (as well as the conversion of organomercurial binding-pocket. Considering the success we obtained with the combined used of quantum chemical and kinetic simulations, we strongly recommend that kinetic simulations be used (in addition to QM methods and experimental analysis of reaction time-coursed) whenever the analysis of reaction mechanism by quantum chemical methods does not afford a clearly preferred pathway.

\section{Acknowledgments}

The authors thank Jan H. Jensen (University of Copenhagen) for helpful comments on this manuscript and James G. Omichinski (University of Montréal) for extensive discussions on the mechanism of MerB inhibition by DTT.

\section{References}

Amovilli C, Mennucci B. 1997. Self-consistent-field calculation of Pauli repulsion and dispersion contributions to the solvation free energy in the polarizable continuum model. The Journal of Physical Chemistry B 5647:1051-1057.

Baker J, Kessi A, Delley B. 1996. The generation and use of delocalized internal coordinates in geometry optimization. Journal of Chemical Physics 105:192-212. 
Barkay T, Miller SM, Summers AO. 2003. Bacterial mercury resistance from atoms to ecosystems. FEMS Microbiology Reviews 27:355-384.

Barone V, Bencini A, Totti F, Uytterhoeven MG. 1997. Comparison between post-Hartree-Fock and DFT methods for the study of strength and mechanism of cleavage of $\mathrm{Hg}$ (SINGLE BOND)C bond. International Journal of Quantum Chemistry 61:361-367.

Becke AD. 1993. Density-functional thermochemistry. III. The role of exact exchange. The Journal of Chemical Physics 98:5648-5652.

Begley TP, Walts AE, Walsh CT. 1986a. Bacterial organomercurial lyase: overproduction, isolation, and characterization. Biochemistry 25:7186-7192.

Begley TP, Walts AE, Walsh CT. 1986b. Mechanistic studies of a protonolytic organomercurial cleaving enzyme: bacterial organomercurial lyase. Biochemistry 25:7192-7200.

Benison GC, Di Lello P, Shokes JE, Cosper NJ, Scott RA, Legault P, Omichinski JG. 2004. A stable mercury-containing complex of the organomercurial lyase MerB: catalysis, product release, and direct transfer to MerA. Biochemistry 43:8333-45.

Choi SC, Chase T, Bartha R. 1994. Metabolic Pathways Leading to Mercury Methylation in Desulfovibrio desulfuricans LS. Applied and environmental microbiology 60:4072-7.

Cossi M, Mennucci B, Pitarch J, Tomasi J. 1998. Correction of cavity-induced errors in polarization charges of continuum solvation models. Journal of Computational Chemistry 19:833-846.

Eto K, Marumoto M, Takeya M. 2010. The pathology of methylmercury poisoning (Minamata disease). Neuropathology : official journal of the Japanese Society of Neuropathology:471479.

Fox B, Walsh C. 1982. Mercuric reductase. Purification and characterization of a transposonencoded flavoprotein containing an oxidation-reduction-active disulfide. J. Biol. Chem. 257:2498-2503.

Häussermann U, Dolg M, Stoll H, Preuss H, Schwerdtfeger P, Pitzer RM. 1993. Accuracy of energy-adjusted quasirelativistic ab initio pseudopotentials. Molecular Physics 78:12111224.

Himo F, Siegbahn PEM. 2003. Quantum chemical studies of radical-containing enzymes. Chemical reviews 103:2421-56.

Hong B, Nauss R, Harwood IM, Miller SM. 2010. Direct measurement of mercury(II) removal from organomercurial lyase (MerB) by tryptophan fluorescence: NmerA domain of coevolved $\gamma$-proteobacterial mercuric ion reductase (MerA) is more efficient than MerA catalytic core or glutathione. Biochemistry 49:8187-96. 
Lafrance-Vanasse J, Lefebvre M, Di Lello P, Sygusch J, Omichinski JG. 2009. Crystal structures of the organomercurial lyase MerB in its free and mercury-bound forms: insights into the mechanism of methylmercury degradation. The Journal of biological chemistry 284:93844.

Ledwidge R, Hong B, Dötsch V, Miller SM. 2010. NmerA of Tn501 mercuric ion reductase: structural modulation of the pKa values of the metal binding cysteine thiols. Biochemistry 49:8988-98.

Ledwidge R, Patel B, Dong A, Fiedler D, Falkowski M, Zelikova J, Summers AO, Pai EF, Miller SM, Conditions G. 2005. NmerA, the metal binding domain of mercuric ion reductase, removes $\mathrm{Hg} 2+$ from proteins, delivers it to the catalytic core, and protects cells under glutathione-depleted conditions. Biochemistry 44:11402-16.

Di Lello P, Benison GC, Valafar H, Pitts KE, Summers AO, Legault P, Omichinski JG. 2004. NMR structural studies reveal a novel protein fold for MerB, the organomercurial lyase involved in the bacterial mercury resistance system. Biochemistry 43:8322-8332.

Li X, Liao R-Z, Zhou W, Chen G. 2010. DFT studies of the degradation mechanism of methyl mercury activated by a sulfur-rich ligand. Physical chemistry chemical physics : PCCP $12: 3961-71$.

Lian P, Guo H-B, Riccardi D, Dong A, Parks JM, Xu Q, Pai EF, Miller SM, Wei D-Q, Smith JC et al. 2014. X-ray Structure of a $\mathrm{Hg}(2+)$ Complex of Mercuric Reductase (MerA) and Quantum Mechanical/Molecular Mechanical Study of $\mathrm{Hg}(2+)$ Transfer between the CTerminal and Buried Catalytic Site Cysteine Pairs. Biochemistry 53:7211-22.

Lin C-C, Yee N, Barkay T. 2012. Microbial Transformations in the Mercury Cycle. In: Liu G, Cai Y, O'Driscoll N eds. Environmental Chemistry and Toxicology of Mercury. Wiley, 155-192.

Mennucci B, Tomasi J. 1997. Continuum solvation models: A new approach to the problem of solute's charge distribution and cavity boundaries. Journal of Chemical Physics 106:51515158.

Ni B, Kramer JR, Bell RA, Werstiuk NH. 2006. Protonolysis of the Hg-C bond of chloromethylmercury and dimethylmercury. A DFT and QTAIM study. The journal of physical chemistry. A 110:9451-9458.

Parks JM, Guo H, Momany C, Liang L, Miller SM, Summers AO, Smith JC. 2009. Mechanism of $\mathrm{Hg}-\mathrm{C}$ protonolysis in the organomercurial lyase MerB. Journal of the American Chemical Society 131:13278-85.

Parks JM, Johs A, Podar M, Bridou R, Hurt RA, Smith SD, Tomanicek SJ, Qian Y, Brown SD, Brandt CC et al. 2013. The genetic basis for bacterial mercury methylation. Science (New York, N.Y.) 339:1332-5. 
Perdew JP. 1991. Unified theory of exchange and correlation beyond the local density approximation. In: Ziesche P, Eschrig H eds. Electronic Structure of Solids '91. Physical Research. Berlin: Akademie Verlag, 11-20.

Peterson K a., Puzzarini C. 2005. Systematically convergent basis sets for transition metals. II. Pseudopotential-based correlation consistent basis sets for the group $11(\mathrm{Cu}, \mathrm{Ag}, \mathrm{Au})$ and 12 (Zn, Cd, Hg) elements. Theoretical Chemistry Accounts 114:283-296.

Pitts KE, Summers AO. 2002. The Roles of Thiols in the Bacterial Organomercurial Lyase (MerB). Biochemistry 41:10287-10296.

Ramos MJ, Fernandes PA. 2008. Computational enzymatic catalysis. Accounts of chemical research 41:689-98.

Riccardi D, Guo H-B, Parks JM, Gu B, Summers AO, Miller SM, Liang L, Smith JC. 2013. Why Mercury Prefers Soft Ligands. The Journal of Physical Chemistry Letters 4:2317-2322.

Schmidt MW, Baldridge KK, Boatz JA, Elbert ST, Gordon MS, Jensen JH, Koseki S, Matsunaga $\mathrm{N}$, Nguyen KA, Su S et al. 1993. General atomic and molecular electronic structure system. Journal of Computational Chemistry 14:1347-1363.

Tomasi J, Persico M. 1994. Molecular Interactions in Solution: An Overview of Methods Based on Continuous Distributions of the Solvent. Chemical Reviews 94:2027-2094.

Truhlar DG. 1998. Basis-set extrapolation. Chemical Physics Letters 294:45-48.

Ullmann GM, Knapp EW. 1999. Electrostatic models for computing protonation and redox equilibria in proteins. European Biophysics Journal 28:533-551.

Varekamp JC, Buseck PR. 1986. Global mercury flux from volcanic and geothermal sources. Applied Geochemistry 1:65-73. 
1

Pathways for Hg removal from MerB, starting from an attacking thiol ("thiol-based" mechanism) or an attacking thiolate ("thiolate-based" mechanism).

In both mechanisms, primed-numbered intermediates arise from the attack of a thiol and a thiolate, whereas intermediates numbered with unprimed numbers arise from the attack of two species with the same protonation state (either two thiols or two thiolates). 

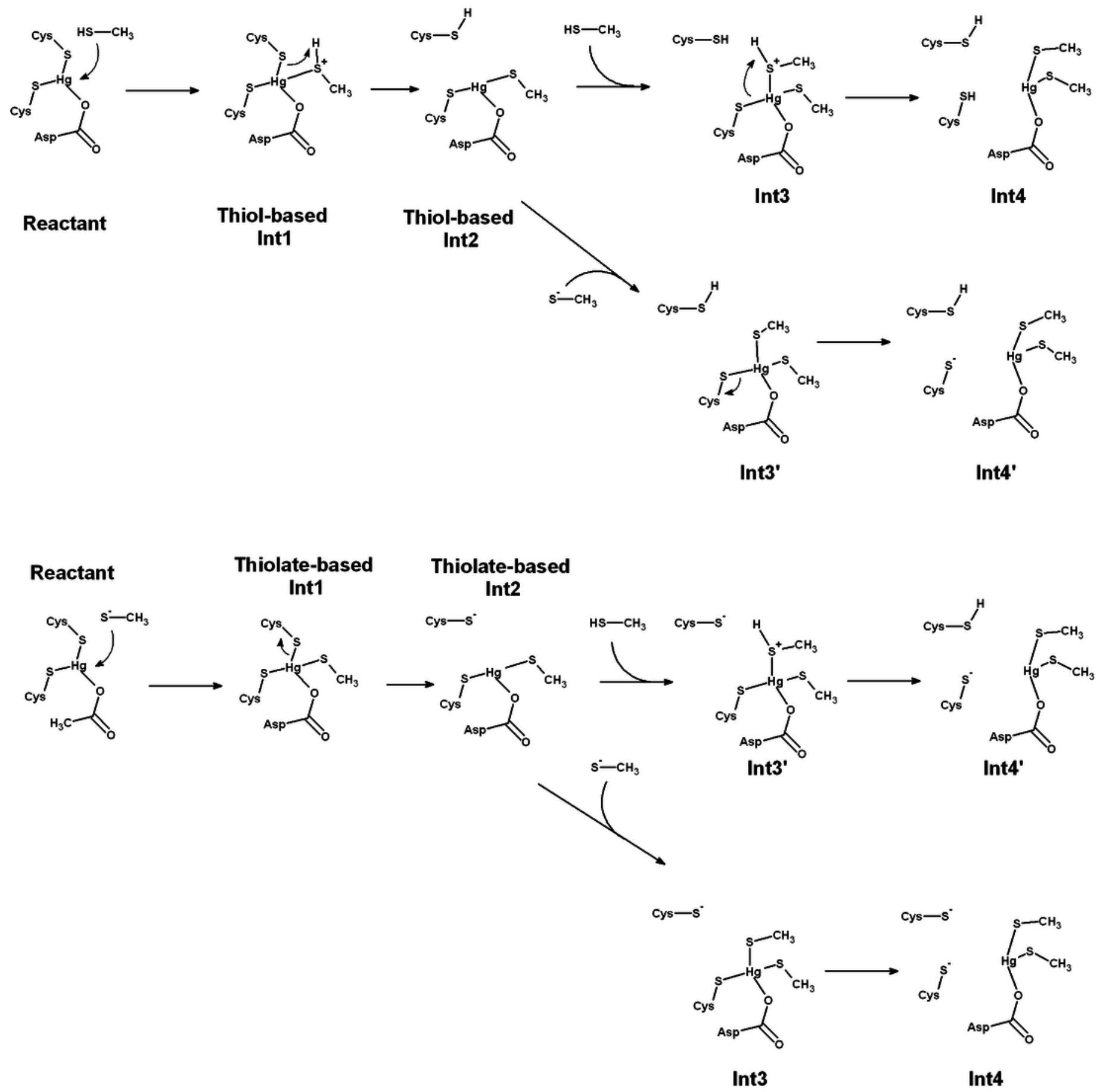
2

Cys-assisted thiol addition to $\mathrm{Hg}^{2+}$

A) pre-reactional complex (Int1); B) $\mathrm{H}^{+}$transfer to Cys 159 (transition state); C) Thiol-based Int2 (Cys96-bound). D) Thiol-based Int2 (Cys96- bound) $\left.+\mathrm{CH}_{3} \mathrm{SH} ; \mathrm{E}\right) \mathrm{H}^{+}$transfer to Cys 96 (transition state); F) Thiol-based Int4 (Asp99-bound). Relevant distances (in ångstrom) are highlighted. Molecules D-E have been rotated counterclockwise ca. 90 around the z-axis, relative to the orientation of molecules $\mathrm{A}-\mathrm{C}$.
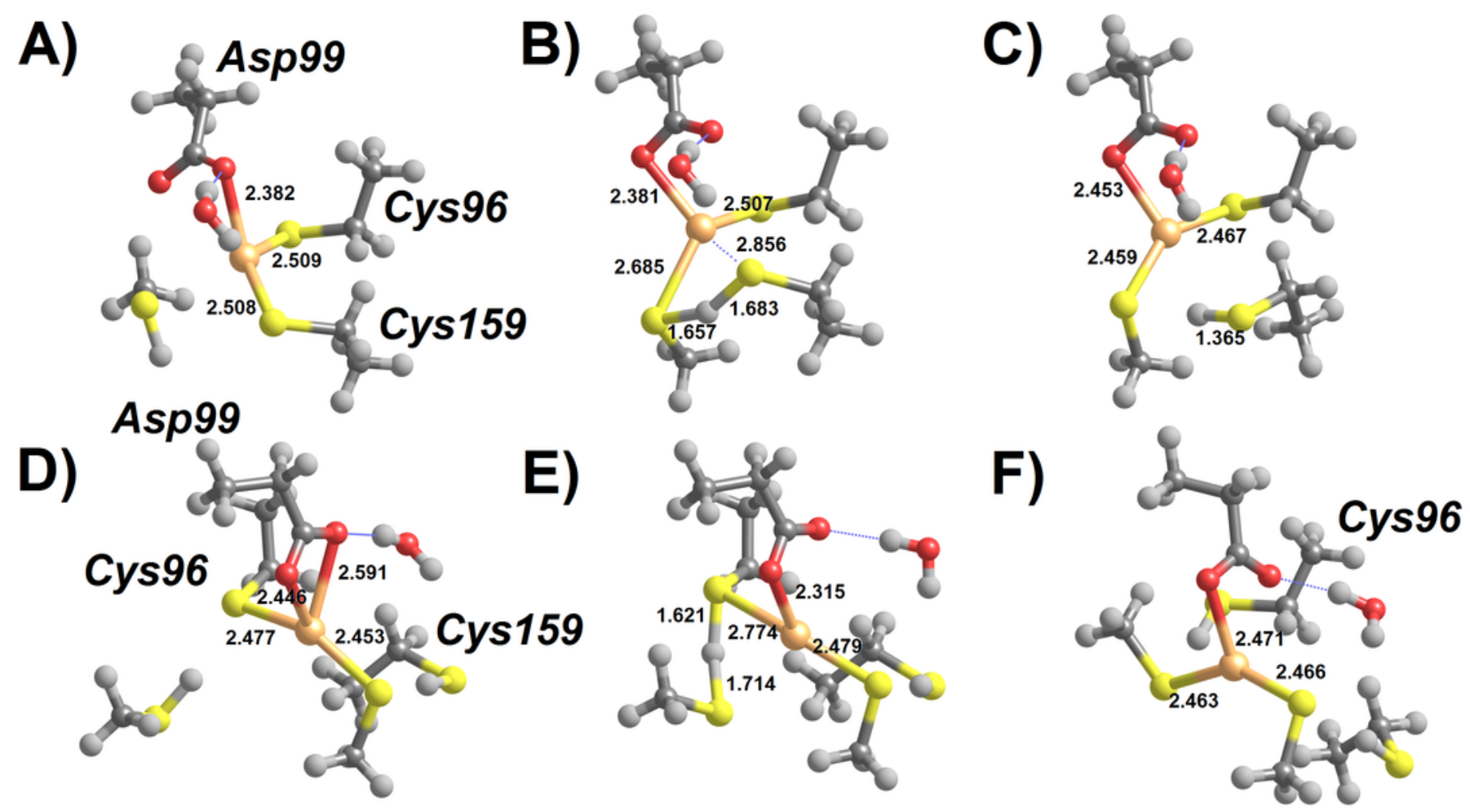


\section{3}

Asp99-assisted thiol addition to $\mathrm{Hg}^{2+}$

A) Asp 99 receives $\mathrm{H}^{+}$from the attacking thiol. B) $\mathrm{H}^{+}$transfer from Asp99 to Cys96 (transition state). C) Thiol-based Int2 (Cys159-bound). D) Thiol-based Int2 (Cys159-bound) $+\mathrm{CH}_{3} \mathrm{SH}$. E) $\mathrm{H}^{+}$transfer from thiol to Asp99 (transition state). F) Thiol-based Int4 (Cys159-bound).

Molecules D-F are depicted as seen from a point of view approximately opposite that used in the depiction of molecules A-C. Relevant distances (in ångstrom) are highlighted.

A)
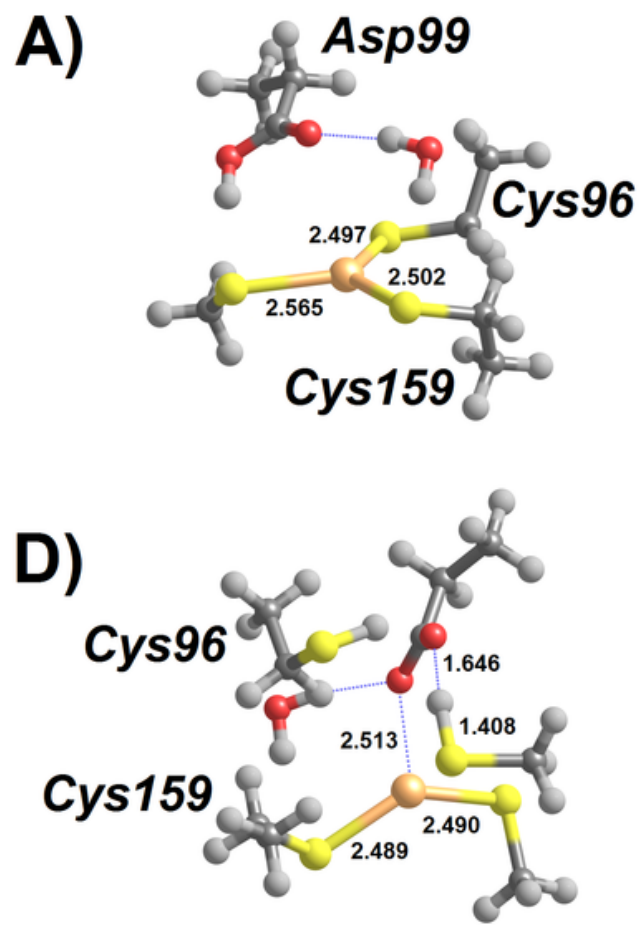

B)

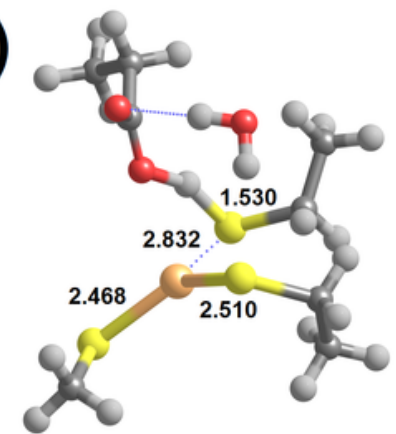

E)

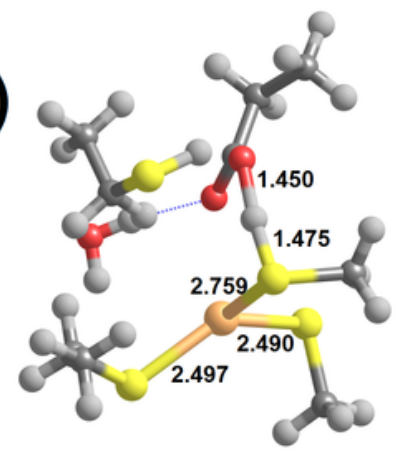

C)

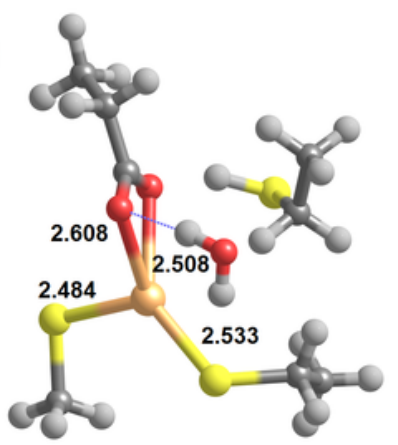

F)

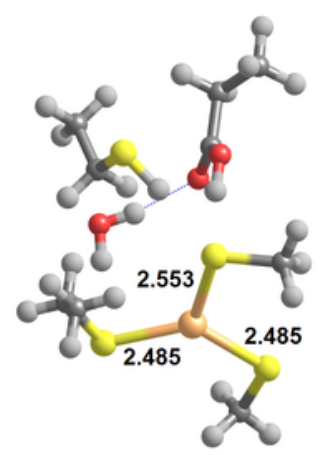


4

Addition of deprotonated thiol to MerB-bound $\mathrm{Hg}^{2+}$

A) Thiolate-based Int1. B) breaking the Cys159-Hg bond (transition state). C) Thiolate-based Int2 (C96-bound). D) breaking the Cys96-Hg bond (transition state) E) Thiolate-based Int2 (C159-bound) Molecules D-E are depicted as seen from a point of view approximately opposite that used in the depiction of molecules A-C. Relevant distances (in ångstrom) are highlighted.

A)

Asp99

B)

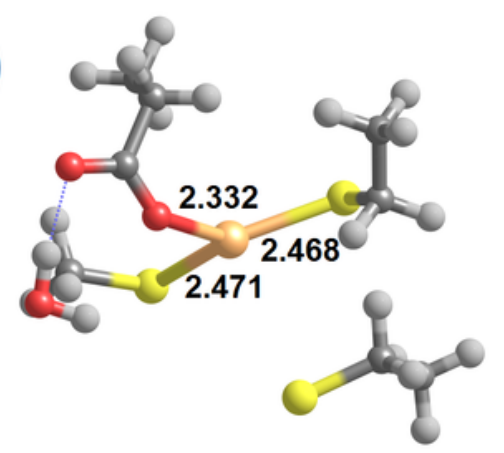

Cys96

2.595

2.618

2.562

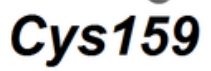

Cys96

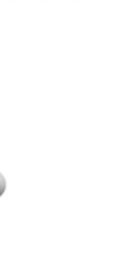

Cys159
D)

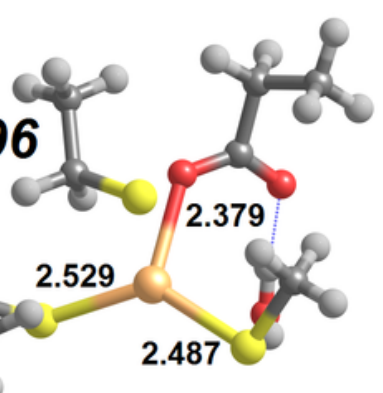

C)

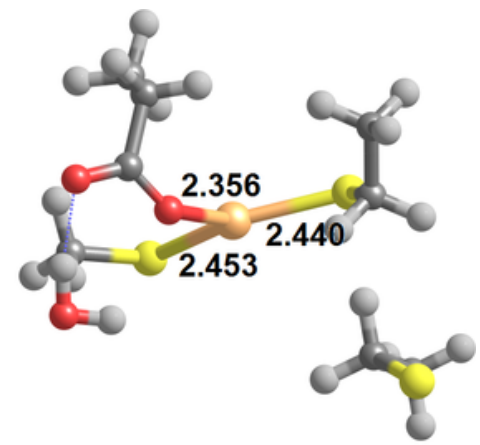

E)

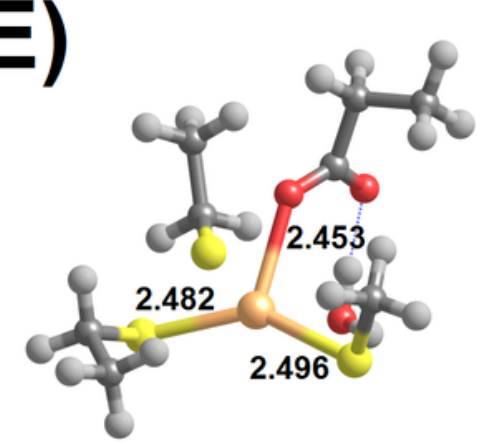




\section{5}

MP2/CBS//B3PW91/6-31G(d) energetic profiles (with $\varepsilon=20$ ) and representative structures of intermediates arising from attack of $\mathrm{Hg}^{2+}$ by a thiol and a thiolate.

A) Energetic profile of Cys159-assisted thiol attack followed by thiolate addition; B) Structure of Int3' arising from Cys159-assisted thiol attack; C) Energetic profile of Asp99-assisted thiol attack followed by thiolate addition; D) Structure of Int3' arising from Asp99-assisted thiol attack followed by thiolate addition; E) Energetic profile of an initial thiolate attack followed by Asp99-assisted thiol addition to $\mathrm{Hg}^{2+}$; F) Structure of the transition state of Asp99-assisted thiol addition to thiolate-based Int 2. Relevant distances (in ångstrom) are highlighted. 

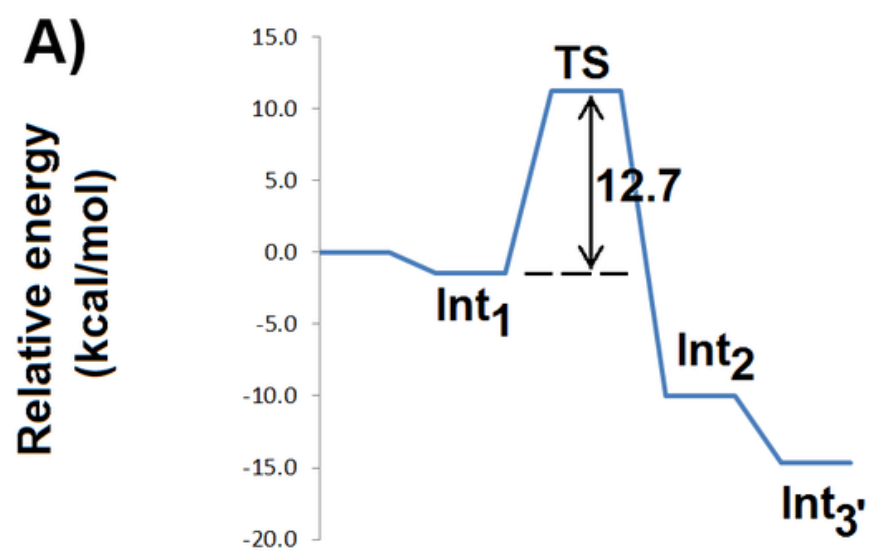

B)
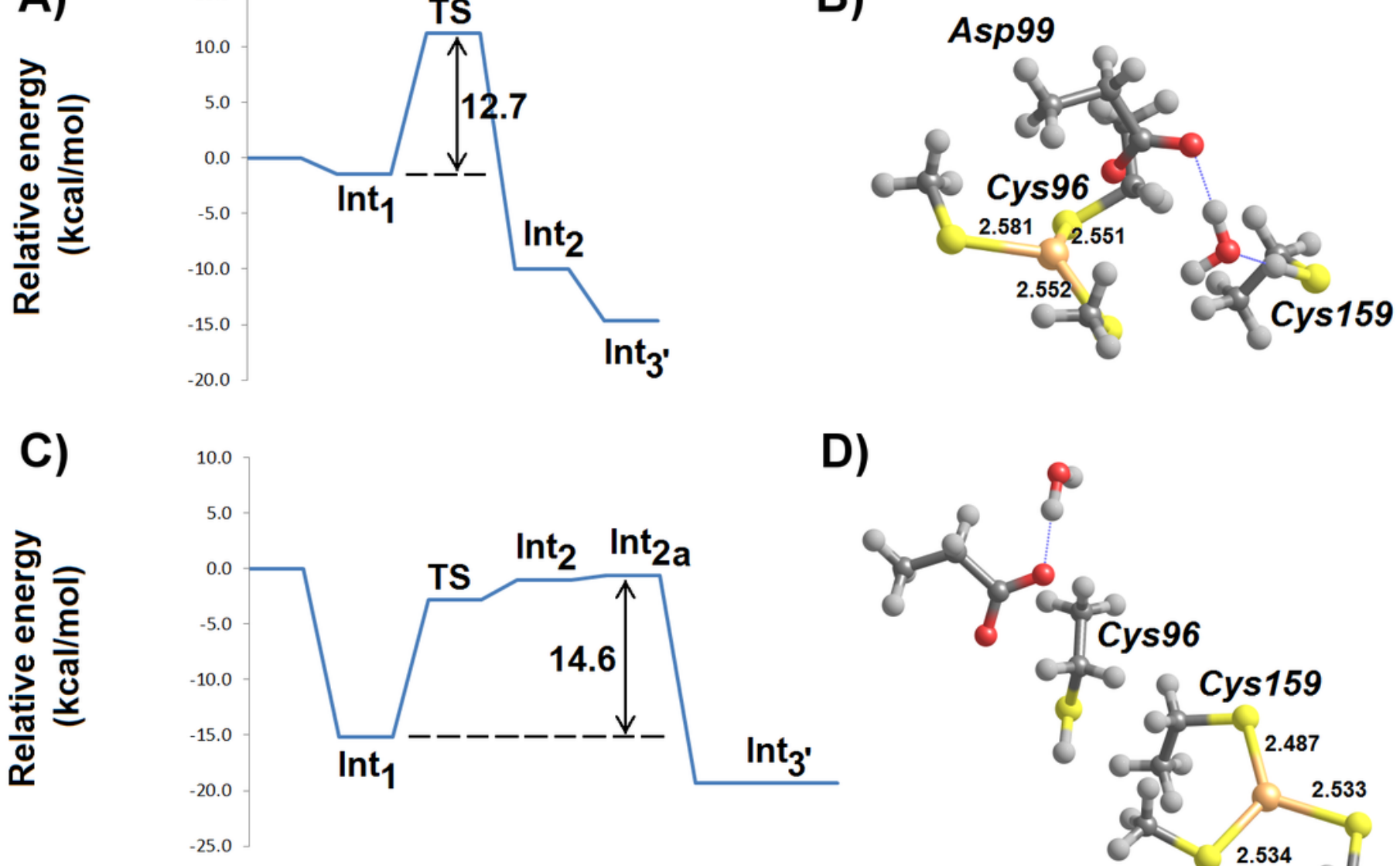

D)

E)
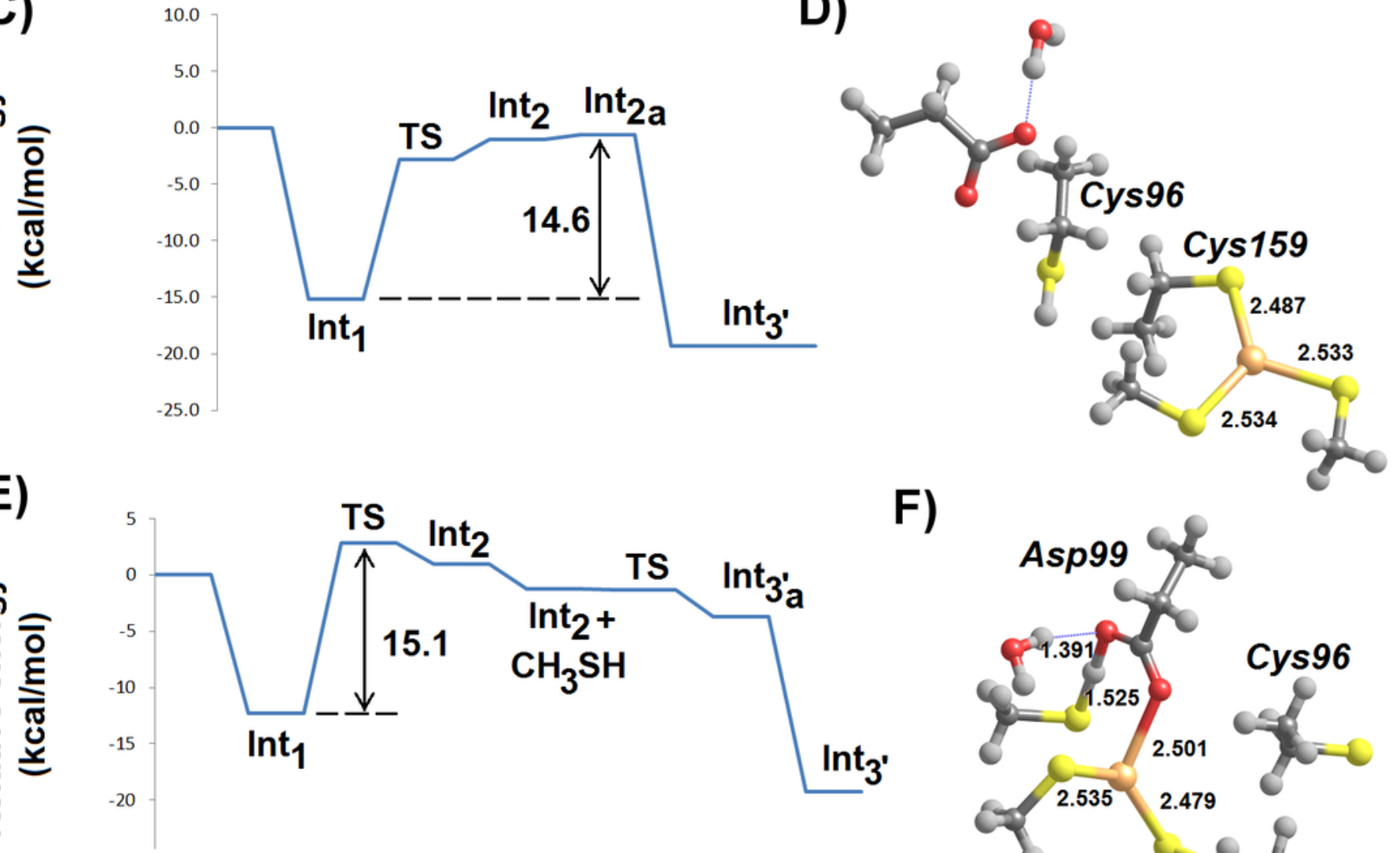

F)

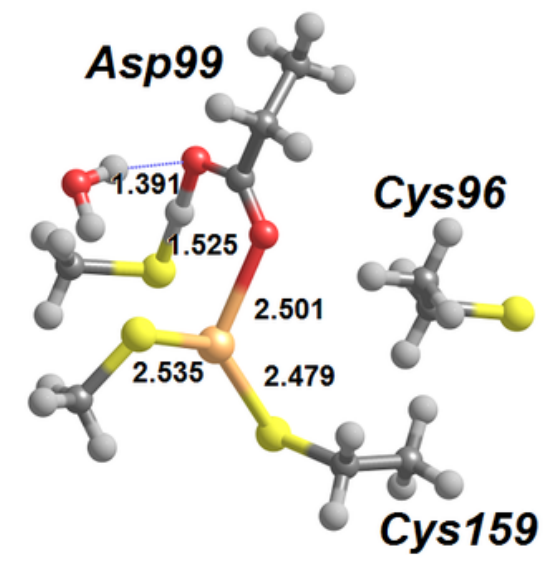


6

$\mathrm{H}_{3} \mathrm{O}^{+}$-assisted removal of $\mathrm{Hg}\left(\mathrm{SCH}_{3}\right)_{2}$ from the MerB active site (compact conformation).

A) Cys96-bound Int3' surrounded by water-solvated $\mathrm{H}_{3} \mathrm{O}^{+}$; B) Proton transfer from $\mathrm{H}_{3} \mathrm{O}^{+}$to Cys96 (Transition state); C) Asp-bound $\mathrm{Hg}\left(\mathrm{SCH}_{3}\right)_{2}$ (Int4). Relevant distances (in ångstrom) are highlighted

A)

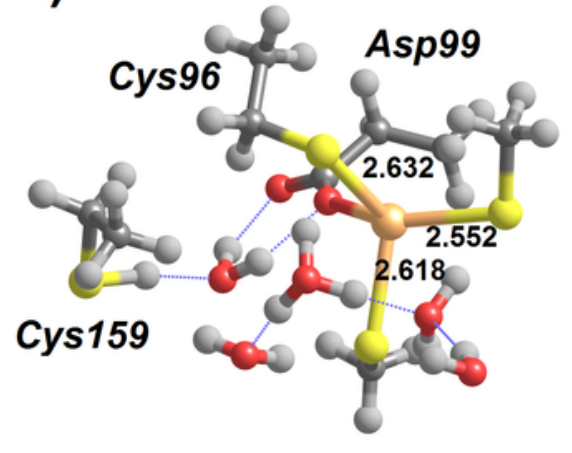

B)

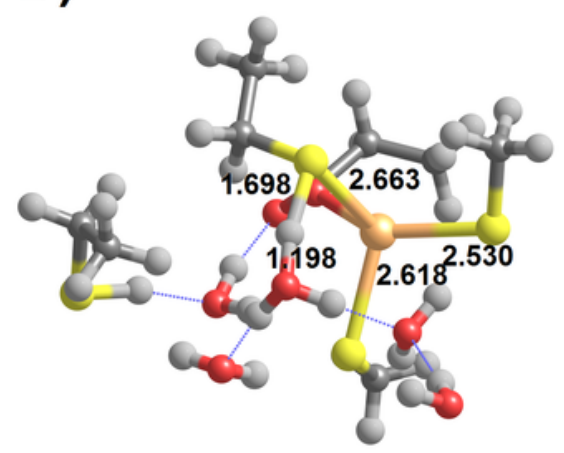

C)

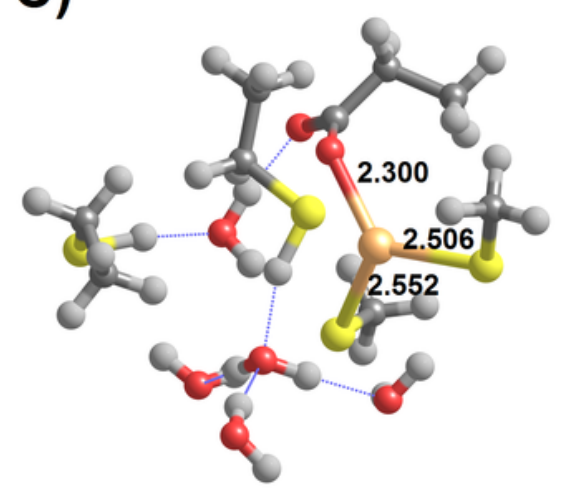




\section{7}

$\mathrm{H}_{3} \mathrm{O}^{+}$-assisted removal of $\mathrm{Hg}\left(\mathrm{SCH}_{3}\right)_{2}$ from the MerB active site (extended conformation).

A) Asp99-protonated Int3' surrounded by water molecules; B) Proton transfer from Asp99 to Cys159 (Transition state); C) Regenerated active site with released $\mathrm{Hg}\left(\mathrm{SCH}_{3}\right)_{2}$. Relevant distances (in ångstrom) are highlighted

A)

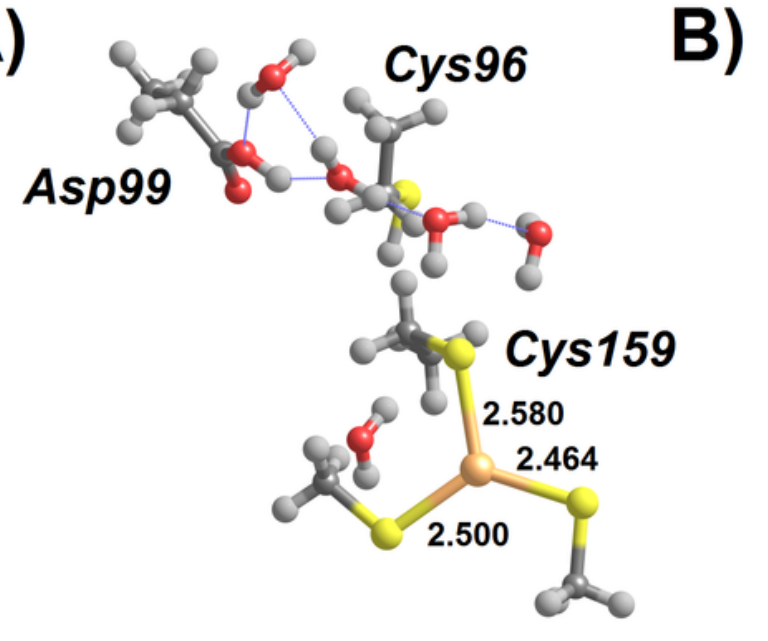

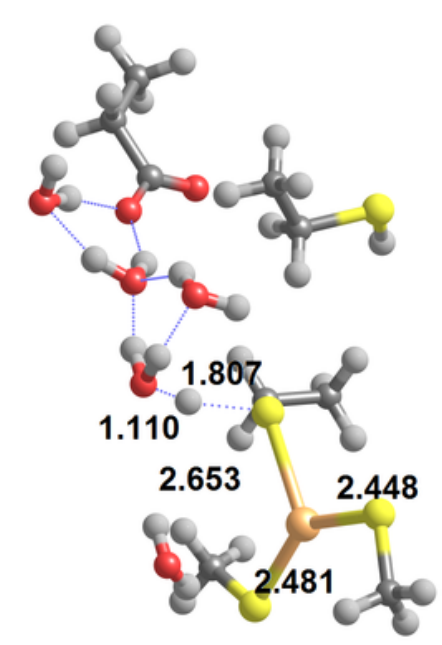

C)

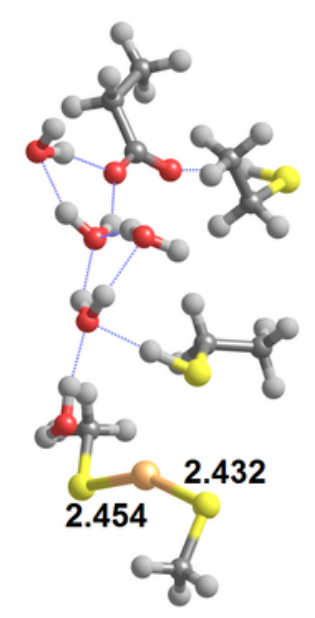




\section{Table $\mathbf{1}$ (on next page)}

Relative enthalpies $\left(\mathrm{kcal} \cdot \mathrm{mol}^{-1}\right)$ of the reaction intermediates in the Cys-assisted thiol addition to MerB-bound $\mathrm{Hg}^{2+}$, computed at the MP2/CBS // B3PW91/6-31G(d) level of theory. 
3 Table 1: Relative enthalpies $\left(\mathrm{kcal}_{\mathrm{mol}}{ }^{-1}\right)$ of the reaction intermediates in the Cys-assisted thiol addition to $\mathrm{MerB}^{-b o u n d ~} \mathrm{Hg}^{2+}$,

4 computed at the MP2/CBS // B3PW91/6-31G(d) level of theory.

\begin{tabular}{|l|l|l|l|l|}
\hline & $\varepsilon=4$ & $\varepsilon=10$ & $\varepsilon=20$ & $\varepsilon=78.36$ \\
\hline Reagent $+\mathrm{CH}_{3} \mathrm{SH}$ & 0.0 & 0.0 & 0.0 & 0.0 \\
\hline Int 1 & -0.6 & -1.2 & -1.5 & -1.7 \\
\hline TS Int1 to Int2 (Cys-96 bound) & 11.7 & 11.4 & 11.3 & 11.1 \\
\hline Int2 (Cys-96 bound) & -8.3 & -9.3 & -10.0 & -10.8 \\
\hline Int2 (Cys-96 bound)+ $\mathrm{CH}_{3} \mathrm{SH}$ & -11.8 & -12.4 & -13.1 & -14.0 \\
\hline TS Int2 to Int4 & & & & 4.2 \\
\hline Thiol-based Int4 (Asp99-bound) & 4.1 & 4.4 & 4.4 & -14.3 \\
\hline Infinitely separated products & -12.8 & -12.8 & -13.5 & -13.3 \\
\hline
\end{tabular}

5 
Table 2 (on next page)

Relative enthalpies ( $\mathrm{kcal}^{\mathrm{mol}}{ }^{-1}$ ) of the reaction intermediates in the Asp99-assisted thiol addition to MerB-bound $\mathrm{Hg}^{2+}$, computed at the MP2/CBS // B3PW91/6-31G(d) level of theory. 
Table 2: Relative enthalpies ( $\mathrm{kcal}_{\mathrm{mol}}{ }^{-1}$ ) of the reaction intermediates in the Asp99-assisted thiol addition to MerB-bound $\mathrm{Hg}^{2+}$,

4 computed at the MP2/CBS // B3PW91/6-31G(d) level of theory.

5

\begin{tabular}{|c|c|c|c|c|}
\hline & $\varepsilon=4$ & $\varepsilon=10$ & $\varepsilon=20$ & $\varepsilon=78.36$ \\
\hline Reagent $+\mathrm{CH}_{3} \mathrm{SH}$ & 0.0 & 0.0 & 0.0 & 0.0 \\
\hline Int 1 (protonated Asp99) & -15.4 & -15.2 & -15.2 & -15.2 \\
\hline TS Int $1 \rightarrow$ Int2 $\left(\mathrm{H}^{+}\right.$moves from Asp99 to Cys96) & -1.7 & -2.4 & -2.8 & -3.2 \\
\hline Int 2 (Cys-159 bound) & -1.0 & -0.9 & -1.0 & -1.1 \\
\hline Int 2 (Cys- 159 bound) $+\mathrm{CH}_{3} \mathrm{SH}$ & -9.6 & -8.6 & -8.3 & -8.2 \\
\hline TS Int2 (Cys-159 bound) to Int4 (Cys159-bound). & -5.5 & -4.7 & -4.5 & -4.4 \\
\hline Thiol-based Int4 (Cys159-bound) & -19.8 & -19.4 & -19.4 & -19.5 \\
\hline
\end{tabular}

6 
Table 3(on next page)

Relative enthalpies $\left(\mathrm{kcal}^{\mathrm{mol}}{ }^{-1}\right)$ of the reaction intermediates in thiolate addition to MerB-bound $\mathrm{Hg}^{2+}$, computed at the MP2/CBS // B3PW91/6-31G(d) level of theory. 
3 MP2/CBS // B3PW91/6-31G(d) level of theory.

\begin{tabular}{|c|c|c|c|c|}
\hline & $\varepsilon=4$ & $\varepsilon=10$ & $\varepsilon=20$ & $\varepsilon=78.36$ \\
\hline Reactant $+\mathrm{CH}_{3} \mathrm{~S}^{-}$ & 0.0 & 0.0 & 0.0 & 0.0 \\
\hline Thiolate-based Int1 & -13.1 & -12.6 & -12.3 & -12.1 \\
\hline Thiolate-based TS $1 \rightarrow 2$ (C96-bound) & 1.8 & 1.8 & 1.8 & 1.9 \\
\hline Thiolate-based Int2 (C96-bound) & -3.7 & -2.6 & -2.2 & -1.9 \\
\hline Thiolate-based Int2 (C96-bound) $+\mathrm{CH}_{3} \mathrm{~S}^{-} \mathrm{TS}$ & 26.8 & 17.1 & 14.0 & 11.8 \\
\hline Thiolate-based Int3 (C96-bound) & 10.6 & 1.5 & -1.3 & -3.2 \\
\hline Reactant $+\mathrm{CH}_{3} \mathrm{~S}^{-}$ & 0.0 & 0.0 & 0.0 & 0.0 \\
\hline Thiolate-based Int1 & -13.1 & -12.6 & -12.3 & -12.1 \\
\hline Thiolate-based TS $1 \rightarrow 2$ (C159-bound) & 1.5 & 2.4 & 2.8 & 3.2 \\
\hline Thiolate-based Int2 (C159-bound) & -0.6 & 0.5 & 1.0 & 1.5 \\
\hline Thiolate-based Int2 (C159-bound) $+\mathrm{CH}_{3} \mathrm{~S}^{-} \mathrm{TS}$ & 32.3 & 21.0 & 17.3 & 14.6 \\
\hline Thiolate-based Int3 (C159-bound) & 14.3 & 3.4 & -0.1 & -2.5 \\
\hline
\end{tabular}




\section{8}

Complete reaction mechanism of the mercury-removing steps in the MerB reaction cycle.

Thiolate-based pathways are depicted in salmon; Asp-assisted thiol addition in sapphire blue; Cys-assisted thiol addition in light olive. Communication between the thiolate-based and the Cys-assisted pathways is not shown explicitly (in contrast to that between thiolate-based and Asp-assisted pathways) but is possible due to the presence of the common intermediate, Int3'(C96bound).

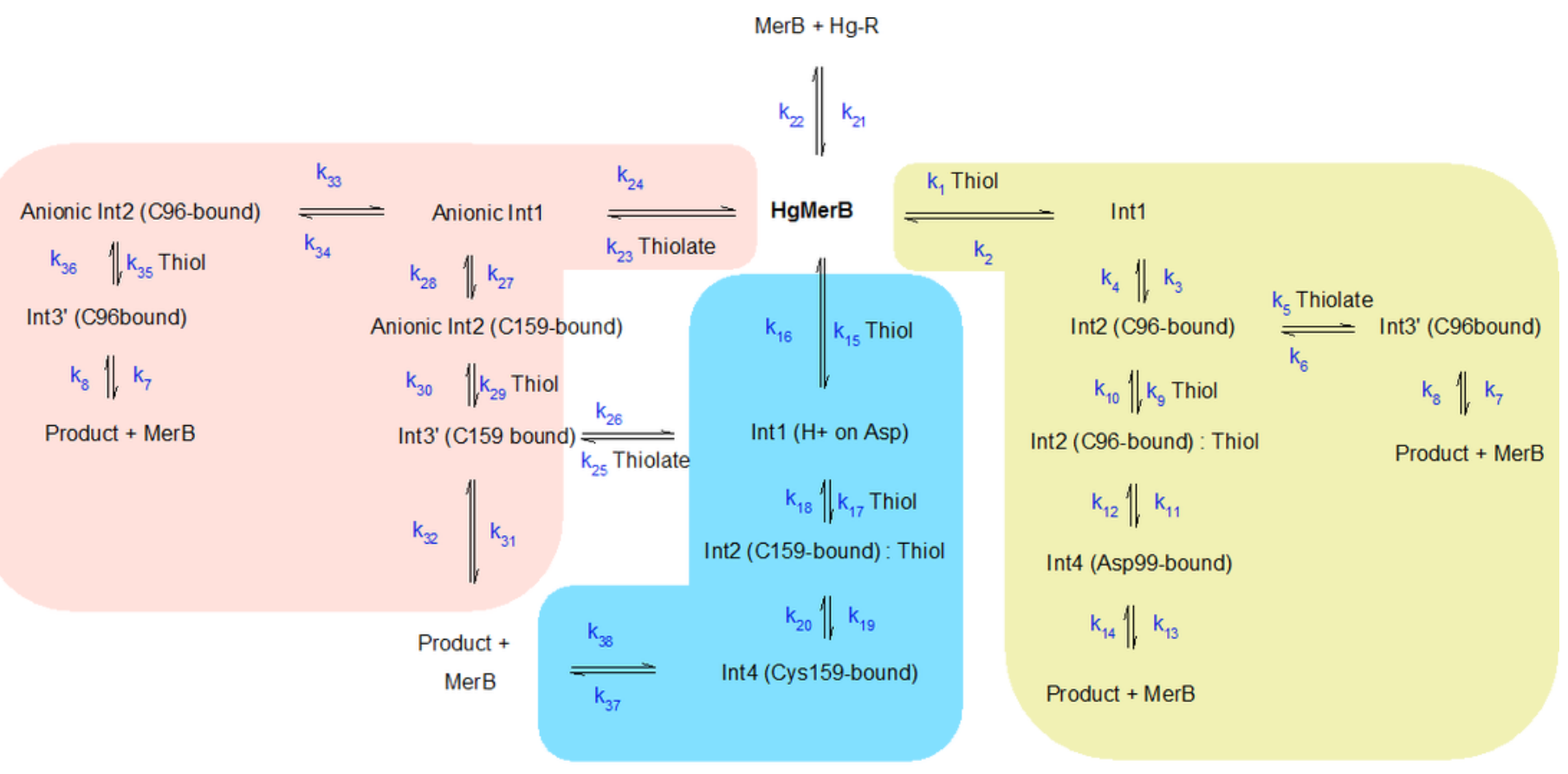




\section{9}

Numerical simulations of different portions of the MerB reaction mechanism in the presence of glutathione, using reaction rates derived from the energies computed by our quantum chemical computations.

A) Thiolate-based pathways only; B) Thiolate-based pathways + conversions to intermediates of the Asp-assisted pathway. Rates of reactions $k_{15} / k_{16}$ set to zero; C) Combined operation of thiolate-based pathways and Asp-assisted thiol addition pathways; D) Thiolate-based pathways + Cys-assisted thiol addition + conversions to intermediates of the Asp-assisted pathway. Rates of reactions $\mathrm{k}_{15} / \mathrm{k}_{16}$ set to zero. Glutathione concentrations are: $0.5 \mathrm{mM}$ (blue), $1.5 \mathrm{mM}$ (yellow), $2.5 \mathrm{mM}$ (red), $5 \mathrm{mM}$ (green), and $10 \mathrm{mM}$ (purple)

A)

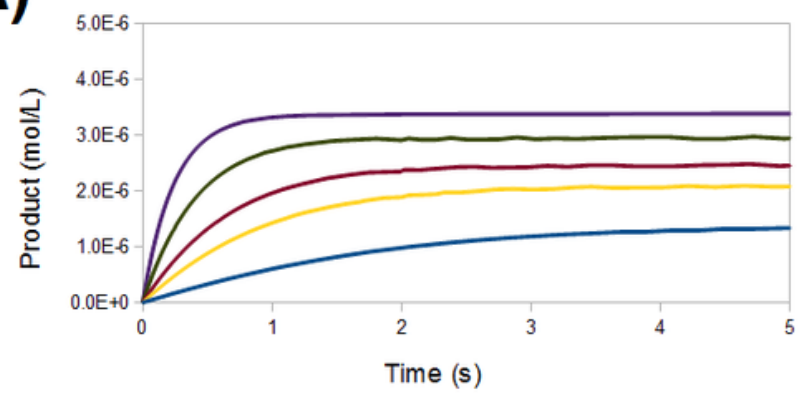

C)

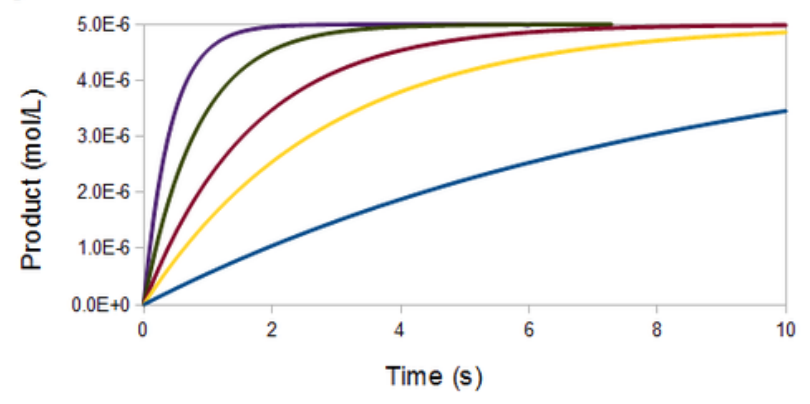

B)

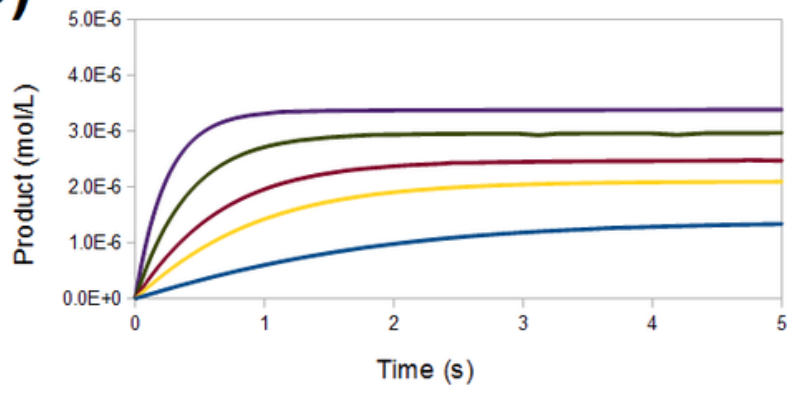

D)

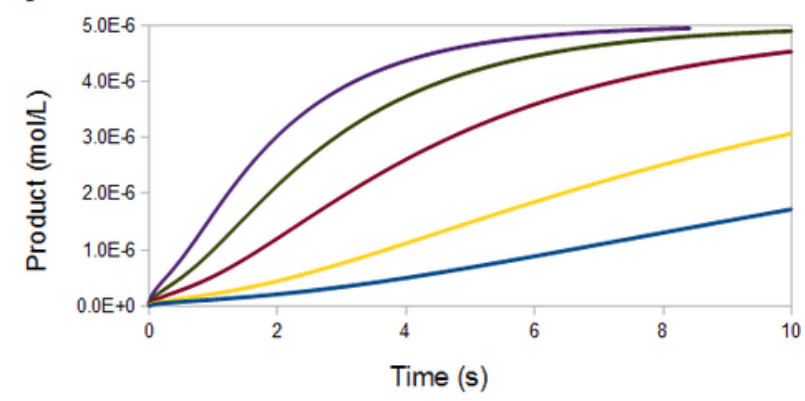

